\title{
Avaliação dos conteúdos de carboidratos solúveis do capim-tanzânia ensilado com aditivos ${ }^{1}$
}

\author{
Carla Luiza da Silva Ávila², José Cardoso Pinto ${ }^{3}$, Valdir Botega Tavares², Ívina Paula \\ Almeida dos Santos ${ }^{4}$
}

\author{
1 Parte da dissertação de Mestrado em Zootecnia, Forragicultura e Pastagens - UFLA. \\ 2 Pós-graduação em Zootecnia - UFLA. \\ ${ }^{3}$ Departamento de Zootecnia - UFLA. \\ ${ }^{4}$ DSc. em Zootecnia - UFLA.
}

RESUMO - Objetivou-se conhecer as variações nos teores de carboidratos solúveis das silagens de capim-tanzânia com aditivos, durante a fermentação, bem como os valores de poder tampão e a relação carboidratos solúveis x poder tampão desta forrageira. O capim-tanzânia (Panicum maximum Jacq. cv. Tanzânia I) foi estabelecido em um Latossolo Roxo Argiloso e colhido com 60-65 dias de crescimento. A forragem foi ensilada em silos experimentais de PVC, adaptados com válvula tipo Bunsen, com capacidade para aproximadamente $3 \mathrm{~kg}$. Os tratamentos consistiram de três aditivos (polpa cítrica, farelo de trigo e fubá de milho), em quatro doses (3, 6, 9 e 12\%) mais uma testemunha sem aditivos e oito tempos de abertura dos silos $(0,1,2,3,7,14,28$ e 56 dias). O delineamento experimental adotado foi o de blocos ao acaso, em esquema fatorial com tratamento adicional $[(3 \times 4)+1] \times 8$ com três repetições. O capim-tanzânia colhido aos 60-65 dias de idade apresentou baixa concentração de carboidratos solúveis e todo o carboidrato da forragem, sem e com aditivos, foi consumido durante o processo de fermentação. Os três aditivos influenciaram os teores de carboidratos solúveis e o poder tampão da forragem, porém, a polpa cítrica foi o aditivo que mais contribuiu para aumentar a concentração de carboidratos solúveis da forragem e reduzir o poder tampão. Aumento da relação carboidratos solúveis:poder tampão propicia melhores condições para que o processo de fermentação resulte em silagem de melhor qualidade.

Palavras-chave: farelo de trigo, fubá de milho, polpa cítrica, silo

\section{Water-soluble carbohydrate contents of tanzaniagrass ensiled with additives}

\begin{abstract}
The aim of this study was to check on the effect of additive addition on the variations in the water soluble carbohydrate contents of the tanzaniagrass silage during the fermentation period, and to know the buffering capacity values and water soluble carbohydrate: buffering capacity ratio of this forage. Tanzaniagrass (Panicum maximum Jacq. cv. Tanzânia I) was established in a Clavey Red Dusk Latosol and harvested at 60-65 day of age. The forage was ensiled in experimental PVC silos, fitted with Type Bunsen valves, with a capacity of about $3 \mathrm{~kg}$ each. The treatments consisted of four doses (3, 6, 9 and 12\%) of three additives (citrus pulp, wheat meal and corn meal), plus one check without additives and 8 times of silo opening $(0,1,2,3,7,14,28$ and 56 days) building up a factorial scheme with an additional treatment $[(3 \times 4)+1] \times 8$ with 3 replicates. The experiment was run in a completely randomized block design. Water soluble carbohydrate content of tanzaniagrass at 60-65 days of age was low and all of it was consumed during the fermentation process, regardless of additive treatments. All three additives, mainly the citrus pulp, favored the water-soluble carbohydrate contents and buffering capacity of the silages. An increase of the water soluble-carbohydrate: buffering capacity ratio contributes to the yield of better quality silage by assisting in the fermentation process.
\end{abstract}

Key Words: citrus pulp, corn meal, silo, wheat meal

\section{Introdução}

A variação na disponibilidade de forragem durante o ano, associada à necessidade de utilização de alimentos de menor custo para ruminantes, tem contribuído para aumentar a procura por novas alternativas de plantas forrageiras para ensilagem. Entre os cultivares do gênero Panicum, o capim-tanzânia destaca-se no cenário nacional, por suas altas produções de matéria seca. O sistema mais indicado para o manejo de Panicum é o pastejo rotacionado, em virtude de suas características de perfilhamento e alta produtividade. 
No entanto, uma das principais dificuldades de exploração intensiva de pastagens por meio de pastejo rotacionado, na maior parte do território brasileiro, é a necessidade de ajuste da lotação das pastagens, em decorrência das variações climáticas durante o ano. Para reduzir as perdas de forragem e o acúmulo de resíduo pós-pastejo, que prejudicam a qualidade da dieta do animal e da rebrota da planta, uma alternativa seria conservar parte e/ou o excesso da forragem produzida no período de maior crescimento das forrageiras na forma de silagem.

Para se obter silagem de gramíneas forrageiras perenes tropicais de boa qualidade nutricional, as gramíneas devem ser colhidas em idades mais jovens ( 60 a 70 dias ou menos). Entretanto, geralmente neste estádio de desenvolvimento, as forrageiras apresentam baixos teores de MS, o que, associado aos baixos teores de carboidratos solúveis das gramíneas tropicais, pode prejudicar o processo de fermentação, comprometendo a qualidade final da silagem.

Segundo Costa et al. (2001), para que o padrão de fermentação durante a ensilagem ocorra de maneira satisfatória, devem ser observados os fatores intrínsecos à planta forrageira e aos fatores do meio. Uma fermentação adequada só é garantida em ambiente de anaerobiose, pela adoção correta das técnicas da ensilagem, como o ponto de colheita, o tamanho da partícula, o rápido carregamento do silo e a compactação para efetiva expulsão do oxigênio do interior do material até a perfeita vedação do silo, a fim de evitar a infiltração de ar e/ou água. Quanto aos fatores intrínsecos à planta, os principais são os teores de carboidratos solúveis e o poder tampão, associados ao teor de matéria seca no momento do corte.

O teor de carboidratos solúveis das plantas forrageiras por ocasião da ensilagem é fundamental para que os processos fermentativos se desenvolvam de forma eficiente (Vilela, 1997), pois são o principal substrato para bactérias acidoláticas produzirem os ácidos, reduzindo o $\mathrm{pH}$ e conservando o material ensilado (Bolsen, 1995). Os principais carboidratos solúveis presentes em culturas forrageiras são frutose, glicose, sacarose e frutosanas, observando-se que sacarose e frutosanas são rapidamente hidrolisados a seus monômeros no momento da colheita (Woolford, 1984).

O poder tampão de uma forragem consiste em sua capacidade de resistir às variações de $\mathrm{pH}$. Grande maior parte das propriedades tamponantes das forragens pode ser atribuída aos ânions (sais ácidos orgânicos, ortofosfatos, sulfatos, nitratos e cloretos), com somente 10 a $20 \%$ resultantes da ação de proteínas vegetais. Quantitativamente, os ácidos mais importantes que ocorrem em gramíneas são o málico, o cítrico e o quinico, destacando-se o ácido oxálico como o mais importante para as gramíneas tropicais (McDonald, 1981). A razão entre carboidratos solúveis e poder tampão é fundamental no processo da ensilagem. Quando essa razão diminui, aumento mínimo no teor de MS é requerido para evitar fermentações indesejáveis no interior do silo (Vilela, 1997). Avaliando duas idades de corte (45 e 60 dias), Coan (2001) observou efeito da idade sobre os teores de MS e carboidratos solúveis e na capacidade tampão, com aumentos de 28,4 para $31,3 \% ; 8,62$ para $8,95 \%$ na MS e de 14,64 para 15,44 emg de $\mathrm{HCl} / 100 \mathrm{~g}$ de MS para o capim-tanzânia e de 24,24 para 25,10\%; 12,38 para $12,43 \%$ na MS e de 8,12 para 20,94 emg de $\mathrm{HCl} / 100 \mathrm{~g}$ de MS para o capim-mombaça, respectivamente. $\mathrm{O}$ autor concluiu que os capins tanzânia e mombaça apresentam MS, carboidratos solúveis e capacidade tampão favoráveis à ensilagem nas duas idades.

O complexo processo de fermentação envolve variações químicas e microbiológicas na massa ensilada e pode resultar em uma silagem de boa ou de má qualidade. Para que se possa intervir no processo, fornecendo condições para boa fermentação, é preciso conhecer o perfil de fermentação de cada planta utilizada.

Os processos biológicos envolvidos na transformação da forragem úmida em silagem em meio anaeróbio e sua utilização são divididos em várias etapas. A primeira iniciase quando a planta é colhida e, durante esta fase, os organismos aeróbios epifíticos convertem carboidratos solúveis em dióxido de carbono, água e calor. As enzimas das plantas também promovem a hidrólise de amido e da hemicelulose a monossacarídeos. Desse modo, o oxigênio contido na massa ensilada é rapidamente consumido após o fechamento do silo. Sob condições ideais de umidade, de tamanho de partícula e de compactação, a atividade aeróbia pode durar poucas horas (McDonald et al., 1981).

Os aditivos devem ser utilizados no processo de ensilagem com o intuito de reduzir os riscos do processo, diminuindo as perdas de MS, melhorando a qualidade higiênica das silagens, limitando as fermentações secundárias, melhorando a estabilidade aeróbia e aumentando o valor nutritivo da silagem produzida (Henderson, 1993). Dentro da classificação dos aditivos (Corrêa \& Pott, 2001), a polpa cítrica, o farelo de trigo e o fubá de milho são classificados como substratos ou fontes de nutrientes, podendo também agir como estimulantes de fermentação, absorventes ou fontes de nutrientes. Muitos estudos realizados com o objetivo de avaliar a qualidade de silagens adicionadas destes aditivos têm mostrado bons resultados.

Considerando o crescente interesse em conservar gramíneas do gênero Panicum e a necessidade de se 
conhecer melhor o processo fermentativo das gramíneas tropicais, realizou-se este trabalho com o objetivo de conhecer as variações nos teores de carboidratos solúveis das silagens de capim-tanzânia com aditivos, durante a fermentação, bem como os valores de poder tampão e a relação carboidratos solúveis x poder tampão desta forrageira.

\section{Material e Métodos}

O experimento foi realizado em área experimental pertencente ao Departamento de Zootecnia da Universidade Federal de Lavras, em Lavras - MG, latitude $21^{\circ} 14^{\prime} \mathrm{S}$, longitude $45^{\circ} 00 \mathrm{~W}$ e altitude de $918,84 \mathrm{~m}$ (Brasil, 1992).

Utilizou-se uma área de capim-tanzânia (Panicum maximum Jacq. cv Tanzânia I) estabelecida em 28/10/1997. Com base na análise química do solo, foi feita a correção da acidez em novembro de 2000, após um corte de limpeza, aplicando-se 1,4 t/ha de calcário dolomítico com PRNT $100 \%$ para elevar a saturação por bases para $60 \%$. Em dezembro de 2000, foi feito um corte de uniformização com roçadeira costal a uma altura de aproximadamente $20 \mathrm{~cm}$ do nível do solo, seguido de adubação de correção, aplicando-se $200 \mathrm{~kg} / \mathrm{ha}$ de N, $50 \mathrm{~kg} / \mathrm{ha}$ de $\mathrm{P} 2 \mathrm{O} 5$ e $80 \mathrm{~kg} / \mathrm{ha}$ de $\mathrm{K} 2 \mathrm{O}$, conforme recomendado pela Comissão de Fertilidade do Solo do Estado de Minas Gerais (1999).

Em fevereiro de 2001, 60 a 65 dias após o corte de uniformização, a forragem foi colhida com roçadeira costal e picada em picadeira estacionária, proporcionando partículas com 10 a $30 \mathrm{~mm}$ para a produção das silagens. Foram utilizados silos de PVC com diâmetro de $10 \mathrm{~cm}$ e altura de $40 \mathrm{~cm}$, adaptados com válvula tipo Bunsen, com capacidade para 2,5 a $3 \mathrm{~kg}$ de silagem. Os tratamentos foram constituídos de combinações entre os diferentes tipos de aditivos (polpa cítrica, farelo de trigo e fubá de milho) com as diversas doses $(3,6,9$ e $12 \%)$, além de um tratamento testemunha, sem aditivo. Foram retiradas amostras da forragem fresca, sem e com aditivos; uma parte foi encaminhada para ofreezer e a outra para a estufa de ventilação forçada $\left(65^{\circ} \mathrm{C}\right.$ por 72 horas), sendo moída e armazenada para análises posteriores.

Para a avaliação do perfil de fermentação das silagens, os silos foram abertos com $0,1,2,3,7,14,28$ e 56 dias de fermentação e, de cada silo, foram retiradas duas amostras, desprezando-se as extremidades da silagem no silo. Destas amostras, uma foi pesada e depois seca em estufa de ventilação forçada $\left(65^{\circ} \mathrm{C}\right)$ e a outra foi colocada em sacos plásticos, devidamente identificados, e congeladas. As análises da forragem fresca, dos aditivos e das silagens foram realizadas no Laboratório de Pesquisa Animal do
DZO-UFLA. As amostras secas em estufa foram trituradas em moinho do tipo Willey com peneira de 30 mesh, armazenadas em potes plásticos devidamente identificados e encaminhadas ao laboratório, para determinação dos teores de MS e carboidratos solúveis (CHOsol), conforme método descrito por Bailey (1981), modificado por Valadares Filho (1997). O princípio desse método consiste na extração dos carboidratos com solução alcoólica a $80 \%$, na reação com solução ácida preparada com antrona e na posterior leitura em espectrofotômetro utilizando-se solução de glicose para o preparo da curva padrão.

O poder tampão foi determinado em amostras congeladas, de acordo com a técnica descrita por Playne \& McDonald (1966). Pesaram-se de 15 a $20 \mathrm{~g}$ do material fresco, efetuando-se a maceração em liquidificador com $250 \mathrm{~mL}$ de água destilada. O maçerado foi titulado primeiramente para $\mathrm{pH} 3,0 \mathrm{com} \mathrm{HCl}$ $0,1 \mathrm{~N}$ para liberar bicarbonatos e $\mathrm{CO} 2 \mathrm{e}$, então, titulado para pH 6,0 com $\mathrm{NaOH} 0,1 \mathrm{~N}$. A capacidade tampão foi expressa como equivalente miligrama (e.mg) de álcali requerido para mudar o $\mathrm{pH}$ de 4,0 para 6,0 por $100 \mathrm{~g}$ de matéria seca, após correção para o valor da titulação de $250 \mathrm{~mL}$ de água.

A relação carboidratos solúveis $\mathrm{x}$ poder tampão foi determinada somente para a forragem antes da ensilagem (tempo 0), calculada dividindo-se o teor de carboidratos solúveis pelo poder tampão.

O delineamento experimental adotado foi o de blocos casualizados, com três repetições, sendo os tratamentos dispostos em esquema fatorial com tratamento adicional do tipo $[(3 \times 4)+1] \times 8-$ três aditivos, quatro doses de cada aditivo, mais uma testemunha e oito tempos de abertura dos silos após a ensilagem. Os dados foram analisados estatisticamente pelos procedimentos de análise de variância, pelo programa SISVAR (Sistema de Análise de Variância para Dados Balanceados), conforme descrito por Ferreira (2000), e o efeito do tempo sobre as variações nos teores de carboidratos solúveis, por meio de equações de regressão.

\section{Resultados e Discussão}

Os níveis de adição dos aditivos na forragem fresca do capim-tanzânia influenciaram significativamente o poder tampão. A interação aditivo $\mathrm{x}$ níveis foi significativa $(\mathrm{P}<0,01)$. Analisando os níveis de adição dentro de cada aditivo, foram observadas diferenças significativas na polpa cítrica $(\mathrm{P}<0,01)$, no farelo de trigo $(\mathrm{P}<0,01)$ e no fubá de milho $(\mathrm{P}<0,05)$, registrando-se comportamento distinto (Figura 1) em cada aditivo.

Verificou-se (Figura 1) resposta quadrática do poder tampão da forragem do capim-tanzânia aos níveis de adição 


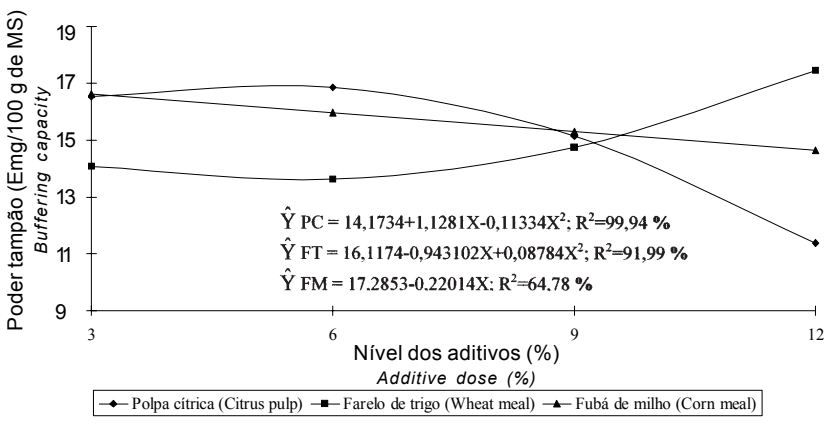

Figura 1 - Efeito dos níveis de aditivos sobre os valores de poder tampão (emg de $\mathrm{NaOH} / 100 \mathrm{~g} \mathrm{MS}$ ) do capimtanzânia.

Figure 1 - Effects of additive doses on the values of buffering capacity (emg of $\mathrm{NaOH} / 100 \mathrm{~g} \mathrm{DM}$ ) of tanzaniagrass.

de polpa cítrica. O nível de adição correspondente ao maior poder tampão (16,98 emg de $\mathrm{NaOH} / 100 \mathrm{~g}$ de MS) pode ser estimado com a concentração de 4,97\%. Quando se utilizou o fubá de milho, notou-se redução linear significativa de 16,62 para 14,64 emg de $\mathrm{NaOH} / 100 \mathrm{~g}$ de MS, sendo esperado, neste caso, redução média de $0,22 \mathrm{emg}$ de $\mathrm{NaOH} / 100 \mathrm{~g}$ de MS para cada unidade de fubá de milho adicionada (Figura 1). O aumento nos níveis de adição do farelo de trigo resultou em resposta quadrática no poder tampão. O nível de adição que corresponde ao valor mínimo do poder tampão (13,58 emg de $\mathrm{NaOH} / 100 \mathrm{~g}$ de MS) foi estimado em $5,36 \%$. A partir daí, notou-se aumento, possivelmente decorrente do maior teor de PB do farelo de trigo, visto que as proteínas fazem parte dos constituintes tamponantes da planta (Woolford, 1984).

Na silagem não tratada, foi determinado valor de poder tampão de 15,74 emg de NaOH/100 g de MS, obtendo-se o menor valor de poder tampão com a adição de $12 \%$ de polpa cítrica (Figura 1).

Imura et al. (2001) encontraram, no capim-guiné (Panicum maximum Jacq. var. maximum), valores de poder tampão de 48,8; 35,9 e 28,9 emg de $\mathrm{NaOH} / 100$ g de MS quando colhido nos estádios vegetativo, início do florescimento e florescimento, respectivamente. Chiou \& Chang (2000), no entanto, registraram valores de poder tampão de 38,0;35,3;25,4 e 20,5 emg de NaOH/100 g de MS no capim-elefante cultivar Napier com a inclusão de 60, 40, 20 e $0 \%$ de grãos de sorgo, respectivamente.

Os ácidos orgânicos e seus sais são os constituintes tamponantes mais importantes das plantas. A fração aniônica de culturas forrageiras, representada pelos ácidos orgânicos, sulfatos, nitratos e cloretos, corresponde a $60-80 \%$ dos constituintes tamponantes na silagem, enquanto as proteínas vegetais, somente a 10-20\% (Dune, 1982, citado por Woolford, 1984).
$\mathrm{Na}$ análise da relação carboidratos solúveis x poder tampão (CHOsol:PT), foi significativa a interação aditivos $\times$ níveis de adição, ocorrendo diferença significativa $(\mathrm{P}<0,01)$ nos valores da relação CHOsol:PT com o aumento dos níveis de adição de polpa cítrica.

Constatou-se efeito quadrático dos níveis de adição de polpa cítrica sobre a relação CHOsol:PT da forragem do capim-tanzânia (Figura 2). O nível de adição que corresponde ao menor valor $(2,95)$ pode ser estimado com o nível de $4,53 \%$ de adição de polpa cítrica. Para os aditivos farelo de trigo e fubá de milho, não foi observada diferença significativa nos valores da relação CHOsol:PT em função dos níveis de adição, com valores médios de 2,07 e 1,92, respectivamente, enquanto, na silagem não tratada, o valor encontrado foi de 1,64.

A relação carboidratos solúveis x poder tampão é um indicador de acidez. Quanto menor essa relação, maior concentração de MS é requerida para evitar fermentações indesejáveis. Neste sentido, a polpa cítrica se destacou, pois foi o aditivo que mais contribuiu para o aumento no teor de carboidratos solúveis, apresentando maior relação CHOsol:PT.

Segundo Weissback \& Honig (1996), citados por Oude Elferink et al. (1999), a concentração de carboidratos solúveis necessários para fermentação adequada depende da capacidade tampão e do teor de matéria seca da cultura a ser ensilada. Esses autores propuseram uma relação entre estes três fatores, caracterizada pela equação: $\mathrm{CF}=\mathrm{MS}+8 \times \mathrm{CS} / \mathrm{PT}$, em que $\mathrm{Cf}$ = coeficiente de fermentação; $\mathrm{MS}=$ matéria seca; $\mathrm{CS}=$ carboidratos solúveis e $\mathrm{PT}=$ poder tampão. Forragens com substratos fermentáveis insuficientes ou teor de matéria seca muito baixo possuem $\mathrm{CF}=35$. Nestas forragens, fermentação suficiente pode ser obtida com o aumento do teor de açúcar do material, pela adição direta de açúcares ou

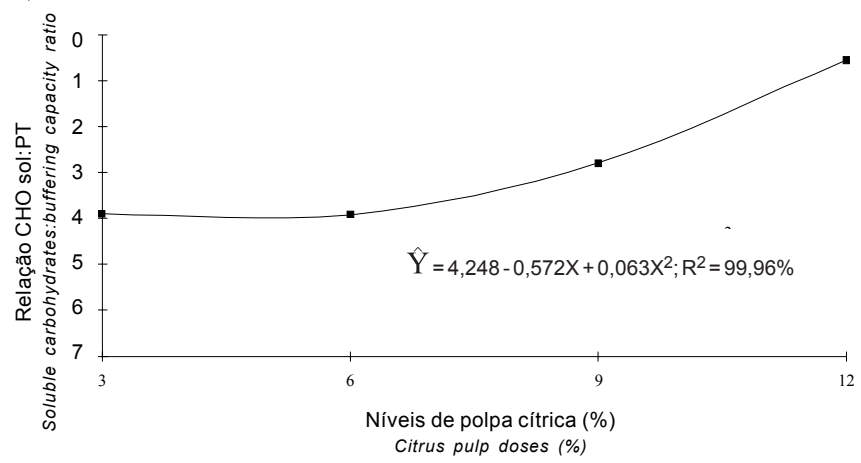

Figura 2 - Efeito dos níveis de polpa cítrica sobre os valores da relação CHOsol:PT da forragem do capim-tanzânia.

Figure 2 - Effects of additive doses on the values of water soluble carbohydrate: buffering capacity ratio of tanzaniagrass. 
pela adição de enzimas que liberem açúcares extras da cultura. Acima deste valor, existe quantidade adequada de substrato para boa fermentação.

Constam na Tabela 1 os valores de coeficiente de fermentação das misturas utilizadas neste experimento. Considerando os coeficientes de fermentação mínimos recomendados por Weissback \& Honig (1996), o capimtanzânia sem aditivos possui quantidades adequadas de substrato para boa fermentação. No entanto, quando os aditivos foram misturados a esta cultura, o coeficiente fermentativo foi maior, observando-se, para a polpa cítrica, tendência de aumento à medida que se aumentou a dose.

Quanto aos teores de CHOsol, houve interação tripla significativa quando os dados foram submetidos à técnica de análise de superfície de resposta (Figuras 3, 4 e 5). O teor de CHOsol do capim-tanzânia antes da ensilagem e sem aditivos (no tempo zero e no nível zero de adição) era de aproximadamente $25 \mathrm{~g} / \mathrm{kg}$ de MS, com algumas variações decorrentes da técnica de análise. Quando a forragem foi adicionada de doses crescentes de polpa cítrica, observou-se aumento no teor de CHOsol para $55 \mathrm{~g} / \mathrm{kg}$ de MS com $12 \%$ de aditivo (Figura 3). A adição de farelo de trigo praticamente não alterou a concentração de CHOsol da forragem em nenhum dos níveis adotados (Figura 4). Para o fubá de milho, foi observada pequena redução, em torno de $5 \mathrm{~g} / \mathrm{kg}$ de $\mathrm{MS}$ de $\mathrm{CHO}$ sol, à medida que se aumentaram os níveis de adição (Figura 5).

O fubá de milho não foi eficiente em aumentar os teores de CHOsol. Entretanto, este aditivo pode melhorar as características de fermentação da forragem, aumentando seu teor de matéria seca no momento da ensilagem. Segundo Ávila (2002), a adição de polpa cítrica, farelo de trigo e fubá de milho melhorou as características fermentativas das silagens de capim-tanzânia, como resultado da queda mais rápida do $\mathrm{pH}$, e diminuiu os valores de $\mathrm{pH}$ e nitrogênio amoniacal da silagem final em comparação à silagem sem aditivos. O autor concluiu que esses aditivos podem melhorar a qualidade de fermentação pelo aumento da pressão osmótica, o que inibe

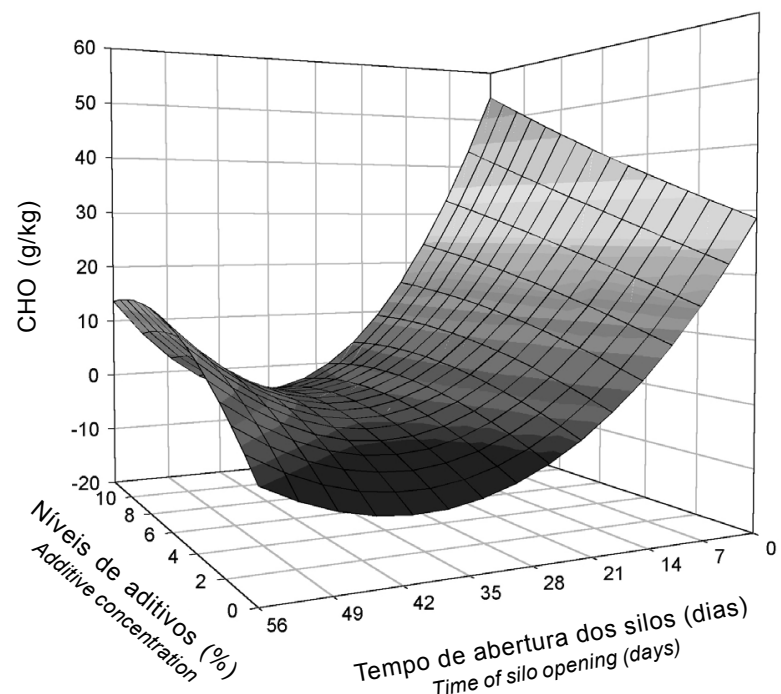

Figura 3 - Efeitos dos níveis de adição de polpa cítrica e do tempo de abertura dos silos sobre a concentração de carboidratos solúveis $(\mathrm{g} / \mathrm{kg}$ de $\mathrm{MS}$ ) da silagem de capim-tanzânia.

Figure 3 - Effects of increasing citrus pulp doses and time of silos opening on water soluble carbohydrate contents ( $\mathrm{g} / \mathrm{kg}$ de DM) of tanzaniagrass silage.

o crescimento de clostrídios, e não diretamente pelo fornecimento de CHOsol para as bactérias acido-láticas.

O amido é a principal fonte de carboidratos do fubá de milho, porém não é aproveitado de maneira eficiente pelas bactérias láticas, embora possa favorecer o processo de fermentação, pela redução do teor de umidade da forragem ensilada. A técnica utilizada neste experimento para a determinação de CHOsol somente detecta carboidratos de cadeia curta, solúveis em água e álcool, não determinando, portanto, os teores de amido contidos na silagem.

Andrade (1995) observou aumento de 11,39 para 15,27\% no teor de CHOsol na MS do capim-elefante quando elevou os níveis de adição de farelo de trigo de 0 para $16 \%$. Esse autor constatou ainda que a sacharina foi o que mais contribuiu para aumentar o teor de CHOsol, elevando em

Tabela 1 - Coeficientes de fermentação do capim-tanzânia sem e com a adição de polpa cítrica, farelo de trigo e fubá de milho, em quatro níveis

Table 1 - Fermentation coefficient of tanzaniagrass and tanzaniagrass with citric pulp, wheat meal and corn meal in four doses

\begin{tabular}{|c|c|c|c|c|c|c|c|c|c|c|c|c|c|}
\hline \multirow[t]{2}{*}{$\begin{array}{l}\text { Mistura }{ }^{1} \\
\text { Blend }\end{array}$} & \multicolumn{4}{|c|}{$\begin{array}{c}\text { Polpa cítrica } \\
\text { Citric pulp }\end{array}$} & \multicolumn{4}{|c|}{$\begin{array}{c}\text { Polpa cítrica } \\
\text { Wheat meal }\end{array}$} & \multicolumn{4}{|c|}{$\begin{array}{c}\text { Fubá de milho } \\
\text { Corn meal }\end{array}$} & \multirow[b]{2}{*}{$0 \%{ }^{2}$} \\
\hline & $3 \%$ & $6 \%$ & $9 \%$ & $12 \%$ & $3 \%$ & $6 \%$ & $9 \%$ & $12 \%$ & $3 \%$ & $6 \%$ & $9 \%$ & $12 \%$ & \\
\hline CF3 & 49,6 & 48,5 & 60,2 & 81,5 & 45,8 & 47,3 & 48,7 & 46,2 & 42,2 & 39,2 & 42,2 & 45,0 & 38,3 \\
\hline
\end{tabular}

1 As misturas correspondem ao capim-tanzânia puro adicionado de polpa cítrica, farelo de trigo e fubá de milho em quatro níveis (3, 6,9 e 12 \%) no momento

da ensilagem.

20 nível $0 \%$ corresponde ao capim-tanzânia sem aditivos.

${ }^{3} \mathrm{CF}=$ coeficiente de fermentação.

1 The blends corresponds to the Tanzaniagrass alone and with citric pulp, wheat meal and corn meal in four doses (3, 6, 9, and 12\%).

2 The level $0 \%$ corresponds to the tanzaniagrass without additives.

${ }^{3}$ Coefficient of fermentation. 


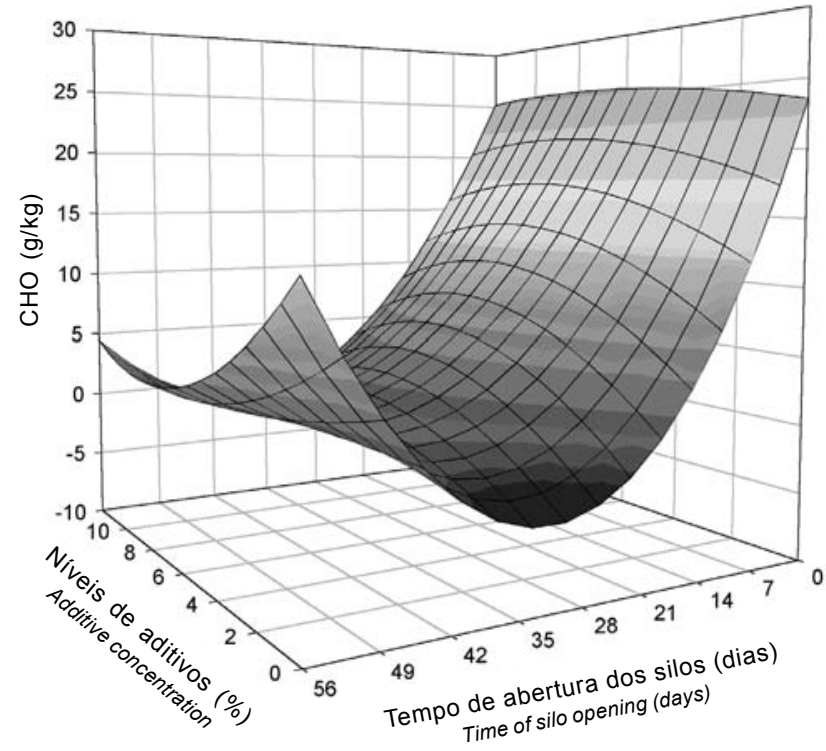

Figura 4 - Efeito dos níveis de adição de farelo de trigo e do tempo de abertura dos silos sobre a concentração de carboidratos solúveis $(\mathrm{g} / \mathrm{kg}$ de $\mathrm{MS})$ da silagem de capim-tanzânia.

Figure 4 - Effects of increasing wheat meal levels and time of silos opening on water soluble carbohydrate contents ( $g / \mathrm{kg}$ de DM) of tanzaniagrass silage.

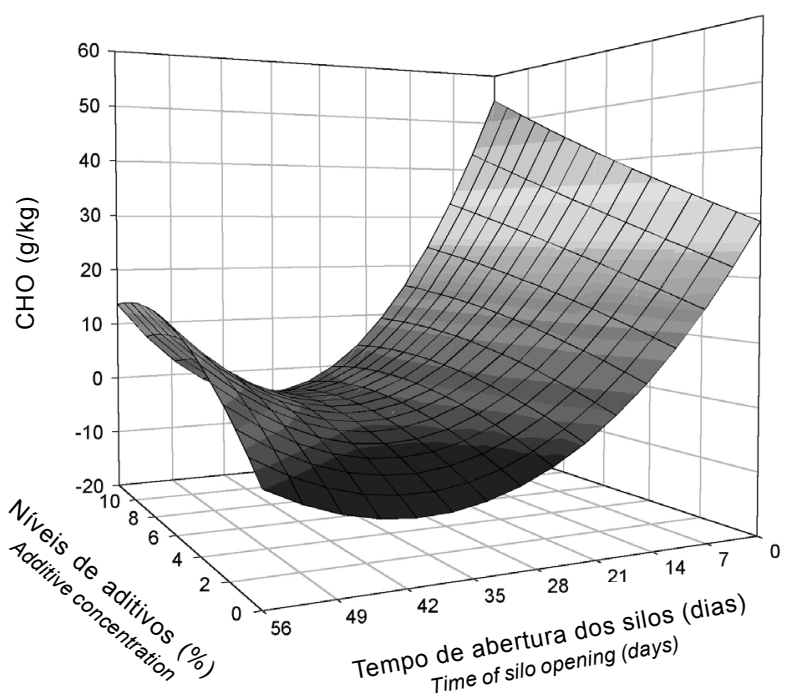

Figura 5 - Efeito dos níveis de adição de fubá de milho e do tempo de abertura dos silos sobre a concentração de carboidratos solúveis ( $\mathrm{g} / \mathrm{kg}$ de $\mathrm{MS})$ da silagem de capim-tanzânia.

Figure 5 - Effects of increasing corn meal levels and time of silos opening on water soluble carbohydrate contents $(\mathrm{g} / \mathrm{kg} D M)$ of the tanzaniagrass silage.
31,14 pontos percentuais, seguida pelo farelo de trigo, com $2,39 \%$, e que a adição de rolão de milho não alterou o teor de $\mathrm{CHO}$ sol do capim-elefante

Quanto aos três aditivos utilizados neste estudo, houve maior efeito dos tempos de abertura que dos níveis de adição, com efeito quadrático em todos os níveis e com menores valores em torno dos 40 dias na polpa cítrica, de 30 a 40 dias no farelo de trigo e de 35 dias no fubá de milho, ocorrendo aumento logo em seguida, de aproximadamente $5 \mathrm{~g} / \mathrm{kg}$ no teor de CHOsol no fubá de milho e no farelo de trigo e $10 \mathrm{~g} / \mathrm{kg}$ na polpa cítrica nos níveis mais altos de adição $(9$ a $12 \%)$ no teor de CHOsol (Figuras 2, 3 e 4).

Esse aumento no teor de carboidratos solúveis ao final da fermentação pode ser decorrente da ação de enzimas ou da hidrólise ácida da hemicelulose, liberando carboidratos solúveis para fermentação. Durante a fase estável de fermentação, pode ainda ocorrer alguma quebra química da hemicelulose liberando açúcares para fermentação (Bolsen, 1995).

Segundo Winters (1987), durante a fase inicial da ensilagem, uma quantidade limitada de nutrientes fica disponível para fermentação, de modo que alguns desses nutrientes são convertidos a ácidos orgânicos, podendo romper membranas das células do mesófilo de forma similar ao ácido fórmico, liberando mais nutrientes para a fermentação. Também é possível que enzimas autocatalíticas de células vegetais, em condições de anaerobiose, contribuam para romper a estrutura celular e disponibilizar nutrientes para a fermentação. Também é provável, segundo o mesmo autor, que ambos os mecanismos atuem na quebra da estrutura celular, em virtude da complexidade do processo de ensilagem.

Praticamente todo o CHOsol da forragem foi consumido durante a fermentação. Apesar do baixo teor de CHOsol da forragem do capim-tanzânia, o processo de fermentação ocorreu de forma a proporcionar silagem de qualidade satisfatória.

\section{Conclusões}

O capim-tanzânia possui baixa concentração de carboidratos solúveis. A polpa cítrica foi o aditivo que mais contribuiu para aumentar a concentração de carboidratos solúveis da forragem e reduzir o poder tampão, proporcionando aumento da relação carboidratos solúveis x poder tampão e melhores condições para que o processo de fermentação resulte em silagem de melhor qualidade. 


\section{Literatura Citada}

ANDRADE, J.B. Efeito da adição de rolão de milho, farelo de trigo e Sacharina na ensilagem do capim-elefante. Botucatu: Universidade Estadual de São Paulo, 1995. 109p. Tese (Doutorado em Nutrição e Produção Animal) - Universidade Estadual de São Paulo, 1995.

ÁVILA, C.L.S. Perfil de fermentação das silagens de capimtanzânia com aditivos. Lavras: Universidade Federal de Lavras, 2002. 82p. Dissertação (Mestrado em Zootecnia) Universidade Federal de Lavras, 2002.

BOLSEN, K.K. Silage: basic principles. In: BARNES, R.F.; MILLER, D.A.; NELSON, C.J. (Eds.) Forages. 5.ed. Ames: Iowa State University, 1995. p.163-176.

BRASIL. Ministério da Agricultura. Normas climatológicas (1961-1990). Brasília: MA/SNI/DNMET, 1992. 84p.

CHIOU, P.W.; CHANG, S.; YU, B. The effects of wet sorghum distillers grains inclusion on napiergrass silage quality. Journal of the Science of Food and Agriculture, v.80, n. 8, p.1199-1205, 2000.

COAN, R.M. Inoculante enzimático-bacteriano, composição química e parâmetros de fermentação das silagens dos capins Tanzânia e Mombaça Jaboticabal: Universidade Estadual de São Paulo, 2001. 38 p. Dissertação (Mestrado em Produção Animal) - Universidade Estadual de São Paulo, 2001.

COMISSÃO DE FERTILIDADE DO SOLO DO ESTADO DE MINAS GERAIS. Recomendação para uso de corretivos e fertilizantes de Minas Gerais: 5 aproximação. Viçosa, MG, 1999. 359 p.

CORRÊA, L.A.; POTT, E.B. Silagem de capim. In: SIMPÓSIO DE FORRAGICULTURA E PASTAGENS, 2., 2001, Lavras. Anais... Lavras: Universidade Federal de Lavras, 2001. p.255-271.

COSTA, C.; MONTEIRO, A.L.G.; BERTO, D.A. et al. Impacto do uso de aditivos e/ou inoculantes comerciais na qualidade de conservação e no valor alimentício de silagens. In: SIMPÓSIO SOBRE PRODUÇÃO E UTILIZAÇÃO DE FORRAGENS CONSERVADAS, 1., 2001, Maringá. Anais... Maringá: Universidade Estadual de Marigá, 2001. p.87-126.
FERREIRA, D.F. Análises estatísticas por meio do SISVAR para windows versão 4.0. In: REUNIÃO ANUAL DA REGIÃO BRASILEIRA DA SOCIEDADE INTERNACIONAL DE BIOMETRia, 45., 2000, São Carlos. Anais... São Carlos: Universidade Federal de São Carlos, 2000. p.225-258.

HENDERSON, N. Silage additivies. Animal Feed Science and Technology, v.45, n.1, p.35-56, 1993.

IMURA, Y.; NAMIHIRA, T.; KAWAMOTO, Y. Fermentation quality of phasey bean and Guineagrass silage. In: INTERNATIONAL GRASSLAND, 19., 2001, São Pedro, São Paulo. Anais... São Pedro, 2001. CD-ROM.

McDONALD, P. The biochemistry of silage. New York: John Wiley, 1981. 207p.

OUDE ELFERINK, S.J.W.H.; DRIEHUIS, F.; GOTTSCHAL, J.C. Silage fermentation processes and their manipulation. In: FAO ELETRONIC CONFERENCE ON TROPICAL SILAGE, 1999, Rome. Silage making in the tropics with emphasis on smallholders. Procedings... Rome: FAO, 2000. p.17-30.

PLAYNE, M.J.; McDONALD, P. The buffering constituints of herbage. Journal of Food Science and Agriculture, v.17, n.6, p.264-268, 1966.

VALADARES FILHO, S.C. Digestibilidade aparente e locais de digetão da matéria seca, energia e carboidratos de feno de soja perene. Belo horizonte: Escola de Veterinária da Universidade Federal de Minas Gerais, 1997. 88 p. Tese (Doutorado em Zootecnia) - Escola de Veterinária da Universidade Federal de Minas Gerais, 1997.

VILELA, D. Utilização do capim-elefante na forma de forragem conservada. In: CARVALHO M.M.; ALVIM, M.J.; XAVIER, D.F. et al. (Eds.) Capim-elefante: produção e utilização. Brasília: EMBRAPA-SPI, 1997. p. 113-160.

WINTERS, A.L.; WHITTAKER, P.A.; WILSON, R.K. Grass and Forage Science, v.42, n.2, p.191-196, 1987.

WOOLFORD, M.K. The silage fermentation. New York: Marcel Dekker, 1984. 350p. 